\title{
Politique suisse et patriarcat: le débat de 1980 sur la rente de retraite des femmes mariées
}

Hadrien Buclin

\section{(2) OpenEdition \\ 1 Journals}

Édition électronique

URL : http://journals.openedition.org/edl/2332

DOI : $10.4000 /$ edl.2332

ISSN : 2296-5084

Éditeur

Université de Lausanne

\section{Édition imprimée}

Date de publication : 15 mars 2020

Pagination : $39-42$

ISBN : 978-2-940331-73-4

ISSN : 0014-2026

\section{Référence électronique}

Hadrien Buclin, « Politique suisse et patriarcat: le débat de 1980 sur la rente de retraite des femmes mariées », Études de lettres [En ligne], 312 | 2020, mis en ligne le 24 mars 2020, consulté le 17

septembre 2020. URL : http://journals.openedition.org/edl/2332 ; DOI : https://doi.org/10.4000/edl. 2332

\section{(c) Études de lettres}




\section{POLITIQUE SUISSE ET PATRIARCAT: \\ LE DÉBAT DE 1980 SUR LA RENTE DE RETRAITE DES FEMMES MARIÉES}

En 1980, les femmes de nationalité suisse disposent des droits politiques depuis seulement neuf ans. Elles restent largement sous-représentées dans les lieux de pouvoir. Le gouvernement n'a alors jamais compté de femme dans ses rangs. Parmi les parlementaires, on compte $10,5 \%$ de femmes au Conseil national et $6,5 \%$ au Conseil des États. Le nouveau mouvement féministe, qui a pris son essor au début des années 1970, peine à concrétiser ses revendications, comme l'illustre le débat parlementaire de 1980 sur la rente des femmes mariées.

En 1978, l'élue du Parti radical-démocratique Cornelia Füeg - exploitante avec son mari d'un domaine agricole, notaire et mère de quatre enfants - dépose une motion demandant que la rente de l'assurancevieillesse et survivants (AVS) des femmes mariées leur soit directement versée. À cette date, c'est en effet le mari qui touche l'argent. Cette réalité administrative est conforme au schéma patriarcal traditionnel: le mari est tenu d'entretenir financièrement la famille, quand son épouse assure les tâches domestiques. Certes, celui-ci doit légalement accorder la moitié de la rente à son épouse. Dans les faits toutefois, la plupart des femmes mariées lésées renoncent à une procédure juridique pour faire valoir leurs droits, soit par méconnaissance, soit par crainte de dissensions au sein du couple.

La proposition de Füeg est acceptée par le Conseil national, mais édulcorée par le Conseil des États, traditionnellement plus conservateur dans la mesure où les petits cantons de Suisse centrale y sont surreprésentés. En juin 1980, le Conseil des États renvoie la proposition au 
gouvernement, mais décide, par une majorité de 24 voix contre 14, de la transformer en un postulat non contraignant pour les autorités.

Pour justifier l'affaiblissement du texte, les parlementaires conservateurs invoquent en particulier le risque que l'individualisation des rentes n'entraîne des dépenses supplémentaires; certaines femmes au foyer ayant peu cotisé, la caisse publique devrait prendre en charge le financement d'une part plus importante de leur retraite. Or, en réaction à la crise économique des années 1970, les cercles conservateurs cherchent à limiter l'extension des prestations sociales et imposent plusieurs plans d'économie ${ }^{1}$. Selon la majorité conservatrice du Conseil des États, il s'agirait donc d'avancer très prudemment dans la mise en œuvre de la proposition portée par Füeg.

Durant le débat, le sénateur socialiste Carl Miville soutient en vain le renvoi du texte sous forme d'une motion contraignante. Il fait valoir qu'un effort financier ne doit pas faire hésiter les élus, car il ne s'agirait que d'une faible compensation des inégalités de salaire; il rappelle que le salaire mensuel médian d'un employé est de 3500 francs, contre seulement 2350 pour une employée. La sénatrice libérale Monique Bauer souligne de son côté combien il est injuste que les femmes mariées, y compris celles qui ont cotisé à l'AVS à travers un emploi salarié, ne puissent pas disposer librement de leur rente, restant dépendantes de ce que leur "concède" leur mari, "plus ou moins généreusement, plus ou moins parcimonieusement». Elle ajoute que "pour la femme au foyer, il faut se rendre compte que le fait de posséder une carte AVS personnelle revêtirait une signification profonde»: "Ne serait-ce pas la meilleure manière de reconnaître la valeur des tâches domestiques, souvent ingrates parce que répétitives!»

Au lendemain du vote, le Journal de Genève, proche des cercles dirigeants, constate que «les conseillers aux États ont fait preuve d'une prudence qui va déplaire, c'est sûr, aux féministes en premier lieu, mais aussi à tous ceux qui estiment que les pouvoirs du mari [...] sont bien trop préservés ». De fait, les autorités ne se privent pas d'exploiter le caractère non contraignant du postulat Füeg, et il est décidé d'attendre la révision du droit matrimonial. Inchangé depuis 1912, celui-ci consacre l'autorité du mari sur son épouse, cette dernière devant notamment demander

I. Voir B. Studer, «Ökonomie der sozialen Sicherheit», p. 952 et M. Leimgruber, Solidarity without the State?, p. 265. 
l'autorisation dudit chef de famille pour l'ouverture d'un compte en banque ou l'exercice d'une activité lucrative.

Lattentisme des autorités illustre bien la synergie négative, analysée par la juriste Patricia Schulz, entre différentes lois discriminant les femmes: on refuse de modifier sur le champ une disposition inégalitaire parce qu'il faudrait au préalable modifier une autre disposition également discriminatoire. Or, le nouveau Code civil garantissant l'égalité des époux n'entre en vigueur qu'en 1988, après avoir passé l'obstacle d'un référendum lancé par la droite conservatrice et des cercles patronaux. Malgré cette réforme du droit matrimonial, les autorités mettent encore sept ans pour concrétiser la proposition Füeg votée en 1980 sous forme de postulat, invoquant cette fois la nécessité d'attendre une révision plus globale de l'AVS, la $10^{\mathrm{e}}$ du nom, qui n'entre en vigueur qu'en 1995.

Finalement, les avancées obtenues en 1995 en matière d'égalité d'accès à la rente et de reconnaissance des tâches éducatives dans le calcul de celle-ci seront payées au prix fort. Une nouvelle crise économique tend alors à éclipser les revendications d'un mouvement féministe pourtant actif, comme l'illustre en 1991 un mouvement de grèves et de manifestations pour l'égalité. En effet, dans le cadre de la $10^{\mathrm{e}}$ révision de l'AVS, les femmes subissent, en parallèle, un report de l'âge donnant droit à la rente. La lente concrétisation du droit à la rente pour les femmes mariées et le prix à payer pour une telle avancée illustrent ainsi l'emprise durable du modèle patriarcal sur la politique suisse, en dépit des bouleversements sociaux post-1968.

Hadrien Buclin

Section d'histoire, Faculté des lettres, Université de Lausanne 


\section{BIBLIOGRAPHIE}

"AVS individuelle: les femmes attendront", Journal de Genève, 4 juin 1980.

Bulletin officiel de l'Assemblée fédérale, 1980, vol. 2, p. 198-203.

Leimgruber, Matthieu, Solidarity without the State? Business and the Shaping of the Swiss Welfare State, 1890-2000, Cambridge, University Press, 2008.

Luchsinger, Christine, Solidarität, Selbständigkeit, Bedürftigkeit: der schwierige Weg zu einer Gleichberechtigung der Geschlechter in der AHV: 1939-1980, Zürich, Chronos, 1995.

Schulz, Patricia, «Une combinaison délétère, ou la néfaste interaction pour les femmes du droit public et du droit privé, en droit suisse", in La Politique des droits. Citoyenneté et construction des genres aux $X I X^{e}$ et $X X^{e}$ siècles, éd. par Hans Ulrich Jost et al., Paris, Kimé, 1994, p. 129-144.

STUDER, Brigitte, "Ökonomie der sozialen Sicherheit", in Wirtschaftsgeschichte der Schweiz im 20. Jahrhundert, hrsg. von Patrick Halbeisen und and., Basel, Schwabe, 2012, p. 923-974. 